\title{
Advancing Social Prescribing with Implementation Science
}

\author{
Laura Gottlieb, MD, MPH, Erika K. Cottrell, PhD, MPP, Brian Park, MD, MPH, \\ Khaya D. Clark, PhD, Rachel Gold, PhD, MPH, and Caroline Fichtenberg, PhD
}

A wealth of emerging evidence on the associations between social determinants of health (SDH) (eg, food, housing, transportation, and education) and health outcomes ${ }^{1-7}$ has fueled a wave of experimentation around identifying and addressing patients' $\mathrm{SDH}$ in the context of clinical care. ${ }^{8}$ The Centers for Medicare and Medicaid Services, the Centers for Disease Control and Prevention, and the $\mathrm{Na}$ tional Academy of Medicine have recommended that high-quality primary care includes documentation of a core set of SDH measures, ideally in electronic health records (EHRs). ${ }^{9-12}$ Due in part to these recommendations, several health sector leaders have developed tools for identifying patients' SDH needs, using validated measures as available (Appendix). ${ }^{13,14}$ These social needs screening tools are now being used to inform clinical interventions, including providing social and economic resources on-site (eg, food boxes) or connecting patients with off-site community-based resources (eg, food banks). Collectively, SDHfocused interventions undertaken in medical settings have been referred to as "social prescribing." 15

This article was externally peer reviewed.

Submitted 28 June 2017; revised 2 October 2017; accepted 4 October 2017.

From Department of Family \& Community Medicine, University of California, San Francisco (LMG); Department of Family Medicine, Oregon Health \& Science University (EKC, KDC); Departments of Family Medicine \& Preventive Medicine, Oregon Health \& Science University (BP); Kaiser Permanente NW Center for Health Research; OCHIN, Inc. (EKC, RG); Center for Health and Community, University of California, San Francisco (CF).

Funding: This work was partially supported by Kaiser Permanente, grant CRN-5374-7544-15320 (LG, CF) and the National Institute of Diabetes and Digestive and Kidney Disease, grant R18DK105463 (EKC, RG).

Conflict of interest: none declared.

Corresponding author: Laura M. Gottlieb, MD, MPH, Department of Family \& Community Medicine, University of California, San Francisco; 3333 California Street, Suite 465, San Francisco, CA 94118. (E-mail: laura.gottlieb@ucsf.edu).
In the United States, much of the experimentation around social prescribing takes place in community health centers ${ }^{16,17}$ where there is a historic precedent for addressing social and economic needs as a core part of primary care. ${ }^{18}$ The Health Resources and Services Administration Bureau of Primary Care requires that federally-qualified health centers provide some services under the umbrella of SDH, such as translation and transportation services that may help to address SDHrelated barriers to care. These kinds of activities are expanding under new federal and state programs that leverage value-based payment models to incentivize more comprehensive, coordinated care, especially for high-risk beneficiaries. For instance, provision 2703 of the Affordable Care Act created an optional Medicaid State Plan benefit to support beneficiaries with chronic diseases $^{19}$; the federal Comprehensive Primary Care $+(\mathrm{CPC}+)$ demonstration project similarly includes a range of value-based payment incentives for improved care management and coordination. ${ }^{20}$ These models support primary care strategies that connect patients with nonclinical social services in addition to coordinating primary, acute, and behavioral health care services.

Despite growing interest in social prescribing, major evidence gaps persist in 2 key areas. First, although findings from some evaluations of SDHrelated interventions suggest that specific programs can decrease social needs and improve health ${ }^{21-24}$, relatively little research addresses the impacts of social prescribing initiatives on patient and provider experience of care, health outcomes, health care costs, and utilization. ${ }^{25}$ Ideally, gaps in effectiveness research will be filled through federal demonstration project evaluations, including evaluations of Health Homes ${ }^{19}, \mathrm{CPC}+$, and the newly launched Accountable Health Communities Program $^{14}$, to the extent that social prescribing com- 
ponents can be distinguished from other care model components. ${ }^{25}$

As the effectiveness research grows in this field, a second major gap in research will become increasingly relevant to practitioners. This gap involves the evidence base on implementation strategies ${ }^{26}$ needed to put these interventions into practice and take them to scale in diverse settings. The rapid proliferation of social prescribing activities in the United States provides an important opportunity for implementation research in this area. This article highlights 3 areas where relevant implementation research is needed and examples of the types of research that could help fill these key evidence gaps (Table 1).

\section{Opportunities for Implementation Science on Social Prescribing}

Social Screening Research

Research is needed on the acceptability of social needs screening in the context of medical care, differences between tools used for capturing information on social needs, and ways that such tools can be adapted to optimize screening uptake in different settings and with different patient populations. New screening initiatives are multiplying around the country and provide ripe opportunities for this research. For example, the National Association of Community Health Centers and other partners have developed a screening tool (PRAPARE) that can help community health centers and other providers collect patients' SDH information. Building on PRAPARE, the nonprofit health care innovation center OCHIN is collaborating with the Kaiser Permanente NW Center for Health Research to study the implementation and use of PRAPARE and other EHR-based tools. (Table 1)

\section{Workforce Research}

Research is also needed on the workforce models that are most feasible and effective to carry out these activities in different settings. Models for social prescribing activities have included both clinical and nonclinical staff, including nurse and social worker case managers ${ }^{36,37}$, student volunteers ${ }^{38}$, community care coordinators ${ }^{39}$, and community health workers. ${ }^{40,41}$ Evidence is needed to better understand the benefits of different workforce models in different settings, identify core training and certification standards across programs, compare implementation strategies within these intervention models, and examine methods to retain and advance nonclinical staff. In one promising example of workforce implementation science, researchers at the University of Pennsylvania have explored strategies to adapt inpatient community health worker programs to outpatient settings. (Table 1)

\section{Payment Models}

Research could also assess how payment models can be structured to incentivize or otherwise support the adoption and spread of social prescribing programs. $^{42}$ These models include federal programs such as $\mathrm{CPC}+$, Health Homes, and Accountable Health Communities, and state/regional programs, including alternative payment methodology demonstrations focused on community health centers ${ }^{43}$, state Medicaid SDH risk adjustment initiatives ${ }^{44}$, and some Medicaid waiver demonstrations. ${ }^{37}$ These programs offer both site-specific and cross-site opportunities to explore which models can catalyze and sustain social prescribing activities, including the workforce and technologic infrastructure needed for intersectoral work. Hennepin Health's payment model, for example, incorporates risk-sharing strategies between participating entities and the reinvestment of annual cost savings into new social prescribing interventions. Together, these have enabled more workforce and data-sharing innovations. Implementation research on this project is ongoing, focused on the impact and sustainability of the interventions developed through reinvestment and on how this model could be replicated in other settings. ${ }^{35}$ (Table 1)

\section{Looking to the Future}

Given the mounting evidence linking SDH and health, health care delivery systems must ask what their roles are in identifying and addressing patients' social and economic needs. The growth of social prescribing pilot programs across the United States can and should be leveraged to explore this looming question. Studies of effectiveness, however, are both necessary and insufficient; they must be aligned with and followed by implementation research that examines program feasibility, including whether and how social prescribing activities can be implemented, disseminated, and sustained in real-world clinical settings. This research should address questions such as (1) which social screening tools are most appropriate for which settings, (2) which implementation approaches maximize adoption, (3) 


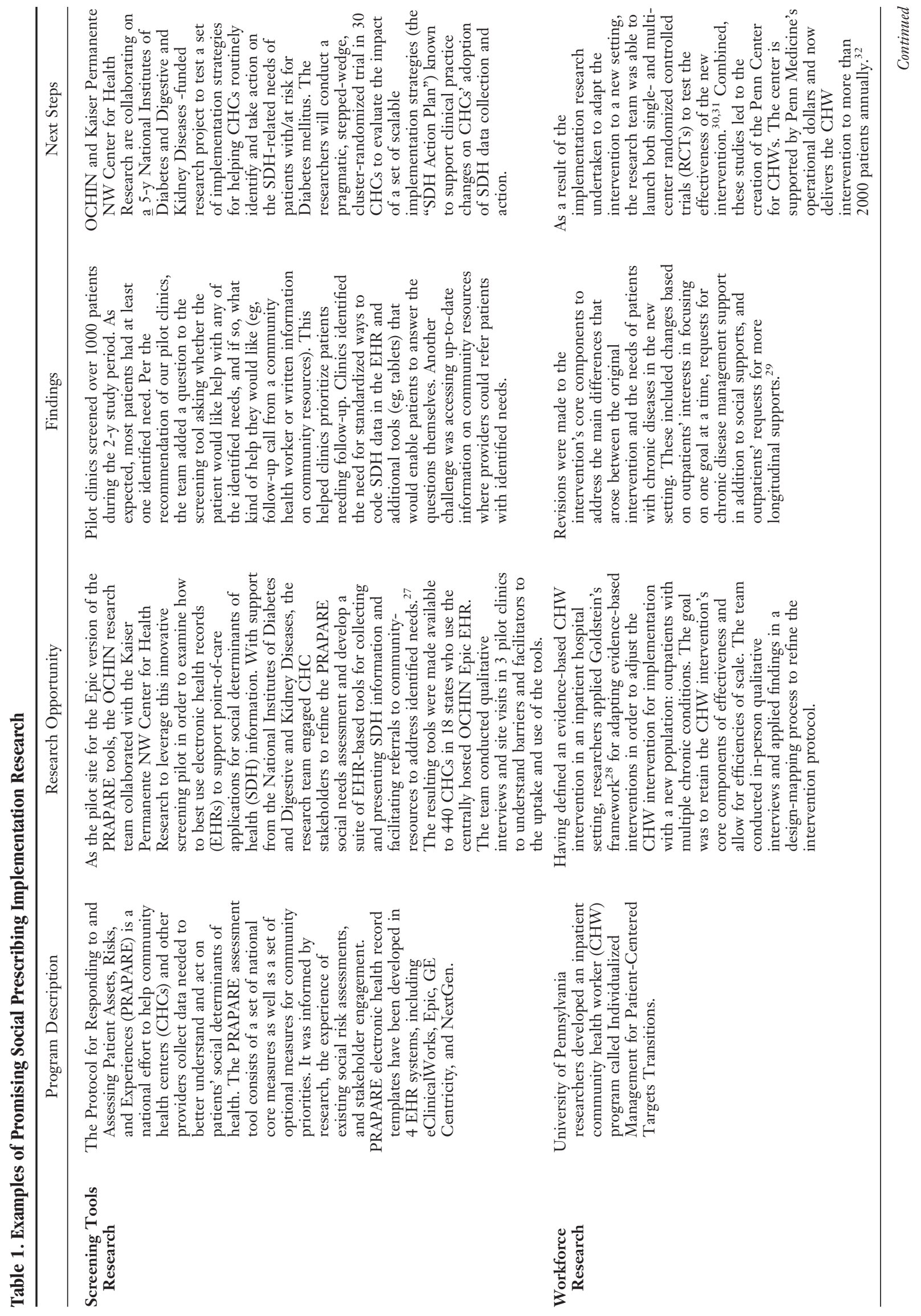




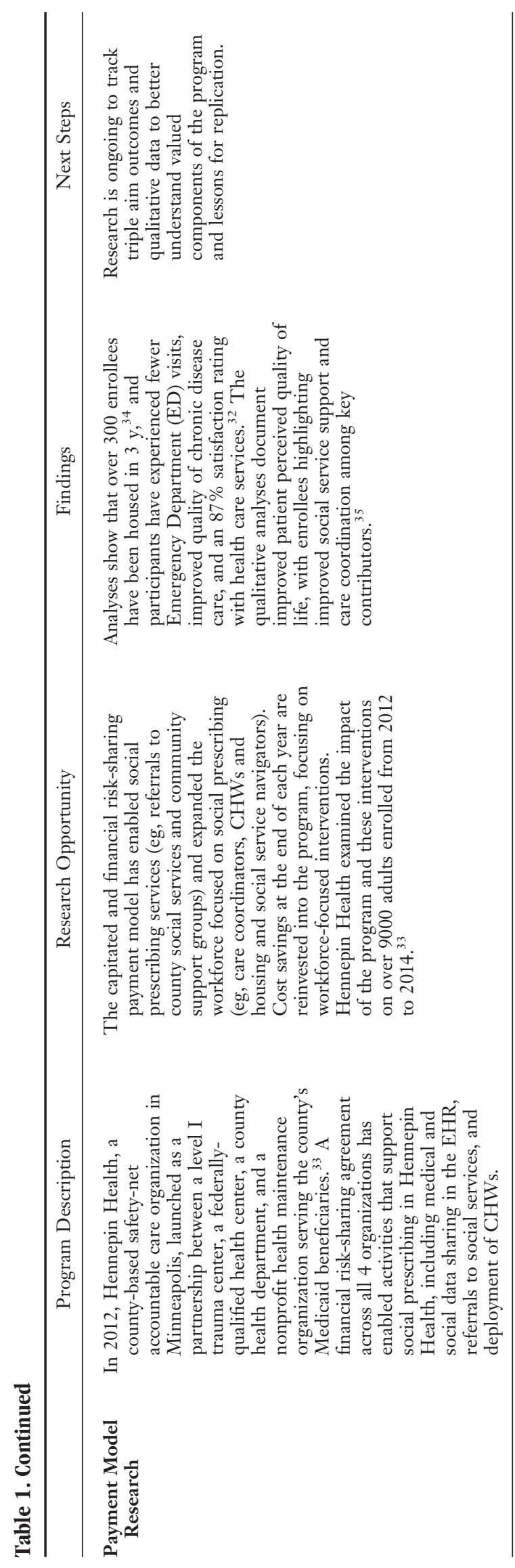

how health information technology could facilitate social screening and community resource linkages, (4) how different workforce models could be leveraged in diverse clinical contexts, and (5) how federal, state, and local payment models can support social prescribing activities over time.

The implementation research examples highlighted here provide insights into how implementation science can support social prescribing's transition from innovative pilot work to sustainable primary care practice. Many other opportunities exist for new research to be conducted in this rapidly evolving field. Advancing such research will require a sustained commitment from many stakeholders, including innovators, health professional organizations, and agencies focused on developing health care standardization and improving quality. Capitalizing on existing practice-based experiments will also require strong research-practice partnerships, which can be facilitated through practicebased research networks with expertise in practicebased methodologies. ${ }^{45}$ The Agency for Health Care Research and Quality has been a strong supporter of such implementation science in primary care. ${ }^{46}$ Recent threats to their budget and overall sustainability directly conflict with this implementation research agenda. ${ }^{47-50}$ Primary care providers and researchers investing in SDH work will need sufficient funding to ensure that the rigorous implementation science needed can prosper in this nascent field.

The authors acknowledge the Starfield Health Equity Summit team Jennifer Devoe, MD, PhD, FAAFP; Viviana MartinezBianchi, MD, FAAFP; Ronya Green, MD; Jennifer Edgoose, MD, MPH; and Sonja Likumahuwa-Ackman, MID, MPH, and CFAR staff, Malachi O'Connor, PhD; Ashleigh Reeves, MA; and Jason Ring, for their contributions to manuscript development. The authors also wish to thank Stephanie Chernitskiy for her assistance in manuscript preparation.

To see this article online, please go to: bttp://jabfm.org/content/ 31/3/315.full.

\section{References}

1. Link BG, Phelan J. Social conditions as fundamental causes of disease. J Health Soc Behav 1995;Spec No:80-94.

2. McGinnis JM, Foege WH. Actual causes of death in the United States. JAMA 1993;270:2207-12.

3. Adler NE, Stewart J. Health disparities across the lifespan: meaning, methods, and mechanisms. Ann N Y Acad Sci 2010;1186:5-23. 
4. McGinnis JM, Williams-Russo P, Knickman JR. The case for more active policy attention to health promotion. Health Aff (Millwood) 2002;21:78-93.

5. Stringhini S, Sabia S, Shipley M, et al. Association of socioeconomic position with health behaviors and mortality. JAMA 2010;303:1159-66.

6. Jemal A, Thun MJ, Ward EE, Henley SJ, Cokkinides VE, Murray TE. Mortality from leading causes by education and race in the United States, 2001. Am J Prev Med 2008;34:1-8.

7. Galea S, Tracy M, Hoggatt KJ, Dimaggio C, Karpati A. Estimated deaths attributable to social factors in the United States. Am J Public Health 2011;101:1456-65.

8. Adler NE, Stead WW. Patients in context-EHR capture of social and behavioral determinants of health. N Engl J Med 2015;372:698-701.

9. Institute of Medicine of the National Academies Committee on the recommended social and behavioral domains and measures for electronic health records. Capturing social and behavioral domains in Electronic Health Records: phase 2. Washington, DC: The National Academies Press; 2014.

10. Centers for Disease Control and Prevention. CMS timeline of important MU dates. https://www.cdc. gov/ehrmeaningfuluse/timeline.html. Published 2016. Accessed June 27, 2017.

11. Centers for Medicare and Medicaid Services. MACRA: delivery system reform, Medicare payment reform. Available from: https://www.cms.gov/Medicare/ Quality-Initiatives-Patient-Assessment-Instruments/ Value-Based-Programs/MACRA-MIPS-and-APMs/ MACRA-MIPS-and-APMs.html. Published 2016. Accessed June 27, 2017.

12. Centers for Medicare and Medicaid Services. CMS quality strategy. Baltimore, MD: Centers for Medicare \& Medicaid Services. Available from: https:// www.cms.gov/medicare/quality-initiatives-patientassessment-instruments/qualityinitiativesgeninfo/ downloads/cms-quality-strategy.pdf. Published 2016. Accessed June 27, 2017.

13. National Association of Community Health Centers, Association of Asian Pacific Community Health Organizations, Oregon Primary Care Association, Institute for Alternative Futures. The protocol for responding to and assessing patients' assets, risks, and experiences (PRAPARE). Available from: http:// www.nachc.org/research-and-data/prapare/. Published 2017. Accessed August 18, 2017.

14. Alley DE, Asomugha CN, Conway PH, Sanghavi DM. Accountable Health Communities-addressing social needs through Medicare and Medicaid. N Engl J Med 2016;374:8-11.

15. Bickerdike L, Booth A, Wilson PM, Farley K, Wright K. Social prescribing: less rhetoric and more reality. A systematic review of the evidence. BMJ Open 7(4):e013384, 2017.

16. Institute for Alternative Futures. Community health centers: leveraging the social determinants of health. Alexandria: Institute for Alternative Futures; 2012. Available from: http://www.altfutures. org/wp-content/uploads/2016/04/2012_Report_ Community-Health-Centers-Leveraging-the-SocialDeterminants-of-Health.pdf. Accessed April 3, 2018.

17. National Association of Community Health Centers. Health centers' role in reducing racial and ethnic health disparities. Bethesda, MD: National Association of Community Health Centers. Available from: http://www.nachc.org/wp-content/uploads/2015/06/ DisparitiesFS.pdf. Published 2008. Accessed June 27, 2017.

18. Adashi EY, Geiger HJ, Fine MD. Health care reform and primary care-the growing importance of the community health center. N Engl J Med 2010; 362:2047-50.

19. Health Homes. Baltimore, MD: Department of Health and Human Services. https://www.medicaid. gov/medicaid/ltss/health-homes/index.html. Accessed September 5, 2017.

20. Sessums LL, McHugh SJ, Rajkumar R. Medicare's vision for advanced primary care: new directions for care delivery and payment. JAMA 2016;315:2665-6.

21. Gottlieb LM, Hessler D, Long D, et al. Effects of social needs screening and in-person service navigation on child health: a randomized clinical trial. JAMA Pediatr. 2016; e162521.

22. Page-Reeves J, Kaufman W, Bleecker M, et al. Addressing social determinants of health in a clinic setting: the WellRx pilot in Albuquerque, New Mexico. J Am Board Fam Med 2016;29:414-8.

23. Berkowitz SA, Hulberg AC, Standish S, Reznor G, Atlas SJ. Addressing unmet basic resource needs as part of chronic cardiometabolic disease management. JAMA Intern Med 2017;177:244-52.

24. Garg A, Toy S, Tripodis Y, Silverstein M, Freeman E. Addressing social determinants of health at well child care visits: a cluster RCT. Pediatrics 2015; 135(2):e296-304.

25. Gottlieb LM, Wing H, Adler N. A systematic review of interventions on patients' social and economic needs. Am J Prev Med. 2017;53:719-729.

26. Proctor EK, Powell BJ, McMillen JC. Implementation strategies: recommendations for specifying and reporting. Implement Sci 2013;8:139.

27. Gold R, Cottrell EK, Bunce A, et al. Development of EHR data tools for collecting, summarizing, and acting on community health center patients' social determinants of health: A stakeholder-led process. J Am Med Inform Assoc. In Press.

28. Goldstein NE, Kemp KA, Leff SS, Lochman JE. Guidelines for adapting manualized interventions for new target populations: a step-wise approach using anger management as a model. Clin Psychol (New York) 2012;19:385-401.

29. Kangovi S, Carter T, Charles D, et al. Toward a scalable, patient-centered community health worker model: adapting the IMPaCT intervention for use in 
the outpatient setting. Popul Health Manag 2016;19: 380-8.

30. Kangovi S, Mitra N, Smith RA, et al. Decisionmaking and goal-setting in chronic disease management: baseline findings of a randomized controlled trial. Patient Educ Couns 2017;100:449-55.

31. Kangovi S, Mitra N, Grande D, Huo H, Smith RA, Long JA. Community health worker support for disadvantaged patients with multiple chronic diseases: a randomized clinical trial. Am J Public Health 2017; e1-e8.

32. Morgan AU, Grande DT, Carter T, Long JA, Kangovi S. Penn Center for Community Health Workers: step-by-step approach to sustain an evidencebased community health worker intervention at an academic medical center. Am J Public Health 2016; 106:1958-60.

33. Sandberg SF, Erikson C, Owen R, et al. Hennepin Health: a safety-net accountable care organization for the expanded Medicaid population. Health Aff (Millwood) 2014;33:1975-84.

34. Hostetter M, Klein S, McCarthy D. Hennepin Health: A care delivery paradigm for new Medicaid beneficiaries. New York, NY: The Commonwealth Fund. Available from: http://www.commonwealthfund.org/ publications/case-studies/2016/oct/hennepin-health. Published 2016. Accessed June 27, 2017.

35. Guzman-Corrales L, Vickery K, Shippee N, et al. Addressing the social and medical needs of complex patients through an accountable care organization: a mixed methods case study of Hennepin Health. North American Primary Care Research Group Annual Meeting; 2016 November 14; Colorado Springs, CO.

36. Pagel L, Schwartz T, Ryan J. The California whole person care pilot program: county partnerships to improve the health of Medi-Cal beneficiaries. Sacramento, CA: Harbage Consulting. Available from: http://harbageconsulting.com/wpcontent/uploads/2017/02/WPC-Summary_Final_ 02282017.pdf. Published 2017. Accessed June 27, 2017.

37. California Department of Health Care Services. Whole person care program: Medi-Cal 2020 waiver initiative Sacramento, CA: California Department of Health Care Services. Available from: http://www.dhcs.ca.gov/ provgovpart/Documents/WPCProgramOverview.pdf. Published 2016. Accessed June 27, 2017.

38. Health Leads. Our model. https://healthleadsusa. org/what-we-do/our-model/. Accessed June 27, 2017.

39. Community Care Coordination Learning Network and The Pathways Community HUB Certification Program. Pathways community HUB manual: a guide to identify and address risk factors, reduce costs, and improve outcomes. Rockville, MD: Agency for Healthcare Research and Quality. Available from: https:// innovations.ahrq.gov/sites/default/files/Guides/ CommunityHubManual.pdf. Published 2016. Accessed June 27, 2017.
40. Jewish Healthcare Foundation, The Network for Excellence in Health Innovation. Community health workers: getting the job done in healthcare delivery. Available from: http://www.nehi.net/writable/ publication_files/file/jhf-nehi_chw_issue_brief web_ready_.pdf. Published 2015. Accessed June $27,2017$.

41. Johnson D, Saavedra P, Sun E, et al. Community health workers and medicaid managed care in New Mexico. J Community Health 2012;37:563-71.

42. Bailit M, Houy M, Waldman B. Three emerging challenges for sustained payment and delivery system reform. Princeton, NJ: Robert Wood Johnson Foundation. Available from: http://www.academyhealth.org/ files/publications/files/FileDownloads/RWJF\%255 FAH\% 2520Emerging\%p2520Challenges\% 2520 FINAL.pdf. Published 2015. Accessed June 27, 2017.

43. Hostetler C, Sisulak L, Cottrell E, Arkind J, Likumahuwa S. Origins in Oregon: the Alternative Payment Methodology Project. Health Affairs Blog. Millwood, VA: Project HOPE: the People-to-People Health Foundation, Inc.; 2014.

44. Ash AS, Mick EO, Ellis RP, Kiefe CI, Allison JJ, Clark MA. Social determinants of health in managed care payment formulas. JAMA Intern Med 2017;177: 1424-1430.

45. Gottlieb L, Ackerman S, Wing H, Adler N. Evaluation activities and influences at the intersection of medical and social services. J Health Care Poor Underserved 2017;28:931-51.

46. Agency for Healthcare Research and Quality. Primary Care Practice-Based Research Networks: An AHRQ Initiative. Available from: https://www.ahrq. gov/research/findings/factsheets/primary/pbrn/ index.html. Published 2012. Accessed June 27, 2017.

47. Science News Staff. What's in Trump's 2018 budget request for science? Science. Available from: http:// www.sciencemag.org/news/2017/05/what-s-trumps-2018-budget-request-science. Published 2017. Accessed June 27, 2017.

48. Lee M, Dickson V. Trump budget would cut $\$ 636$ billion from HHS agencies. Modern Healthcare. Available from: http://www.modernhealthcare.com/ article/20170522/NEWS/170529978. Published 2017. Accessed June 27, 2017.

49. Powderly H. Trump's budget cuts HHS spending by $\$ 15$ billion, rolls AHRQ into the NIH. Healthcare Finance. Available from: http://www.healthcarefinancenews.com/ news/trumps-budget-cuts-hhs-spending-15-billion-rollsahrq-nih. Published 2017. Accessed June 27, 2017.

50. Fox M. Trump budget cuts to scientific, medical research would have 'devastating' effect: Experts. NBC News. Available from: http://www.nbcnews.com/ health/health-news/trump-budget-cuts-scientificmedical-research-will-have-devastating-effect-n734401. Published 2017. Accessed June 27, 2017. 


\begin{tabular}{|c|c|c|c|}
\hline $\begin{array}{l}\text { Social and Economic Risk } \\
\text { Screening Tool }\end{array}$ & $\begin{array}{l}\text { Recommended Social and } \\
\text { Behavioral Domains and } \\
\text { Measures for Electronic } \\
\text { Health Records }\end{array}$ & $\begin{array}{l}\text { PRAPARE: Protocol for Responding } \\
\text { to and Assessing Patient Assets, } \\
\text { Risks, and Experiences }\end{array}$ & $\begin{array}{l}\text { Accountable Health } \\
\text { Communities } \\
\text { Screening Tool }{ }^{14}\end{array}$ \\
\hline Total number of questions & 24 & 21 & 10 \\
\hline \multicolumn{4}{|l|}{ Domain } \\
\hline Residential address & $\bullet$ & $\bullet$ & \\
\hline Race/ethnicity & $\bullet$ & $\bullet$ & \\
\hline Alcohol Use & $\bullet$ & & \\
\hline Tobacco use and exposure & $\bullet$ & & \\
\hline Depression & $\bullet$ & & \\
\hline Education & $\bullet$ & $\bullet$ & \\
\hline Financial resource strain, sverall & $\bullet$ & & \\
\hline Household income & & $\bullet$ & \\
\hline Household size & & $\bullet$ & \\
\hline Housing & & $\bullet$ & $\bullet$ \\
\hline Food & & $\bullet$ & $\bullet$ \\
\hline Clothing & & $\bullet$ & \\
\hline Utilities (phone, gas, electric) & & $\bullet$ & $\bullet$ \\
\hline Medicine/health care & & $\bullet$ & \\
\hline Child care & & $\bullet$ & \\
\hline Transportation & & $\bullet$ & $\bullet$ \\
\hline Neighborhood safety & & $\bullet *$ & \\
\hline Interpersonal violence/safety & $\bullet$ & $\bullet *$ & $\bullet$ \\
\hline Physical activity & $\bullet$ & & \\
\hline Social connections/isolation & $\bullet$ & $\bullet$ & \\
\hline Stress & $\bullet$ & $\bullet$ & \\
\hline Migrant/seasonal farmworker & & $\bullet$ & \\
\hline Veteran status & & $\bullet$ & \\
\hline Primary language & & $\bullet$ & \\
\hline Incarceration history & & $\bullet *$ & \\
\hline Refugee status & & •* & \\
\hline Insurance status & & $\bullet$ & \\
\hline
\end{tabular}

*Optional question in Protocol for Responding to and Assessing Patient Assets, Risks, and Experiences (PRAPARE). 